\title{
Microstructural and Chemical Analysis of AgI Coatings Used as a Solid Lubricant in Electrical Sliding Contacts
}

Jonas Lauridsen, Per Eklund, Jun Lu, A Knutsson, A M Andersson and Lars Hultman

\section{Linköping University Post Print}

N.B.: When citing this work, cite the original article.

The original publication is available at www.springerlink.com:

Jonas Lauridsen, Per Eklund, Jun Lu, A Knutsson, A M Andersson and Lars Hultman, Microstructural and Chemical Analysis of AgI Coatings Used as a Solid Lubricant in Electrical Sliding Contacts, 2012, Tribology letter, (46), 2, 187-193.

http://dx.doi.org/10.1007/s11249-012-9938-3

Copyright: Springer Verlag (Germany) http://www.springerlink.com/

Postprint available at: Linköping University Electronic Press http://urn.kb.se/resolve?urn=urn:nbn:se:liu:diva-76935 


\title{
Agl as a solid lubricant in electrical contacts
}

\author{
J. Lauridsen ${ }^{\text {a* }}$, P. Eklund ${ }^{\text {a }}$, J. Lu ${ }^{\text {a }}$, A. Knutsson ${ }^{\text {b }}$, M. Odén ${ }^{\text {b }, ~ R . ~ M a n n e r b r o ~}{ }^{\text {, }}$, \\ A. M. Andersson ${ }^{\text {, }}$, and L. Hultman ${ }^{\text {a }}$ \\ ${ }^{a}$ Linköping University, Thin Film Physics Division, Department of Physics, Chemistry, \\ and Biology (IFM), Linköping University, SE-581 83 Linköping, Sweden \\ ${ }^{b}$ Linköping University, Nanostructured Materials, Department of Physics, Chemistry and \\ Biology(IFM), Linköping University, SE-581 83 Linköping, Sweden \\ ${ }^{c}$ ABB Components, Lyviksvägen 10, SE-771 41, Ludvika, Sweden \\ ${ }^{d}$ ABB Corporate Research, Forskargränd 7, SE-721 78, Västerås, Sweden
}

\begin{abstract}
AgI coatings have been deposited by electroplating on $\mathrm{Ag}$ plated $\mathrm{Cu}$ coupons. Electron microscopy shows that the coatings consist of weakly agglomerated AgI grains. X-ray diffraction, differential scanning calorimetry, thermogravimetry and mass spectrometry show that the AgI exhibits a reversible transformation from hexagonal to cubic phase at $150{ }^{\circ} \mathrm{C}$. AgI starts to decompose at $150{ }^{\circ} \mathrm{C}$ with an accelerating rate up to the $\mathrm{AgI}$ melting temperature $\left(555^{\circ} \mathrm{C}\right)$, where a complex-bonded hydroxide evaporates. Ag-pin-on-disk testing shows that the iodine addition to Ag decreases the friction coefficient from 1.2 to 0.4. The contact resistance between $\mathrm{AgI}$ and $\mathrm{Ag}$ becomes less than $100 \mu \Omega$ after $\sim 500$ operations as the $\mathrm{AgI}$ deagglomerates and $\mathrm{Ag}$ is exposed on the surface, and remains low
\end{abstract}

\footnotetext{
* Corresponding author. E-mail address: jonla@ifm.liu.se (J. Lauridsen).

Linköping University, IFM, SE-581 83 Linköping, Sweden. Tel.: +46 13282976; Fax: +46 13137568.
} 
during at least 10000 reciprocating operations. This makes AgI suitable as a solid lubricant in electrical contacts.

Keywords: Silver Iodide, Friction coefficient, Contact resistance, TEM, Phase transformation, DSC

\section{Introduction}

Today, noble metals are the most common materials in electrical contact applications; because of their low resistivity, ductility, and oxidation resistance [1]. The contacting surfaces are typically pressed against one another until at least one of them yields plastically to increase the electrical contact area to conduct current from one contact member to the other. The tribological situation of such non-lubricated systems is severe with high wear, and the life time of a sliding noble-metal electrical contact is short [2]. To increase the durability of the electrical contacts, new functional materials can be a solution [3-6]. A liquid lubricant could be an option, but this requires maintenance of the contacts, making it less productive. A solid lubricant is another alternative; however, this adds a technological challenge since it should both decrease the friction coefficient and protect against wear and corrosion, while retaining the electrical properties of the contact material. Conventional solid lubricants, e.g., graphite and $\mathrm{MoS}_{2}$, have too high electrical resistivity [7], and degrade rapidly in oxidizing environments [8].

Previous work has shown that the friction coefficient and the wear of an Ag contact can be decreased and still have good electrical performance if an AgI coating is deposited on 
top of the contact [9]. The mechanisms behind this improvement, however, are not known, but could be related to the structure and stability of the materials in contact.

Therefore, the present work investigates the microstructure and phase transformation, and contact resistance properties of AgI coatings deposited on Ag-plated $\mathrm{Cu}$ coupons for different annealing and wear conditions, to improve the knowledge about the behavior of AgI in such electrical contact system.

\section{Experimental details}

$2 \mu \mathrm{m}$ thick AgI coatings were deposited onto an Ag-plated $\mathrm{Cu}$ coupon by an electrochemical process. The coupon acted as anode, where it was put in a $0.2 \mathrm{M} \mathrm{KI}(\mathrm{aq})$ electrolyte with a Pt net as cathode. A current density of $3.0 \mathrm{~mA} / \mathrm{cm}^{2}$ was applied during 4 min under ambient temperature and pressure.

X-ray diffraction (XRD) was performed in situ during heat treatment in a X'pert MPD Bragg-Brentano, theta-theta diffractometer with $\mathrm{Cu}-\mathrm{K} \alpha \mathrm{X}$-rays operating at $45 \mathrm{kV}$ and 40 mA, equipped with a Bühler HDK 2.4 high-temperature high-vacuum chamber with a Be-window. The samples were placed in the vacuum chamber and surrounded by two Ta filaments. The chamber was then evacuated to a base pressure of $10^{-3} \mathrm{~Pa}$. Both filaments were resistively heated and connected to thermocouples. At each temperature three 25min scans were made, then the temperature was increased rapidly. At temperatures between $130-160{ }^{\circ} \mathrm{C}$, the temperature was increased with $5{ }^{\circ} \mathrm{C} /$ step. From $160{ }^{\circ} \mathrm{C}$ the temperature was increased to $200{ }^{\circ} \mathrm{C}$, and then increased in steps of $100{ }^{\circ} \mathrm{C}$ up to $500{ }^{\circ} \mathrm{C}$. 
Differential scanning calorimetry (DSC), thermogravimetry (TG) and mass spectrometry (MS) were performed using a Netzsch STA-449 C equipped with a Netzsch QMS-403 C mass spectrometer. The sensitivity and temperature was calibrated using melting standards of $\mathrm{Bi}, \mathrm{In}, \mathrm{Sn}, \mathrm{Zn}$, and $\mathrm{Al}$. AgI powder was scratched from the sample with a scalpel, meaning that the fraction of $\mathrm{Ag}$ from the underlying layer is unknown. Approximately $20 \mathrm{mg}$ of powder was used for one run, and the test was performed in a 50 $\mathrm{ml} / \mathrm{min}$ protective Ar flow. The samples were heated to the maximum temperature of $600{ }^{\circ} \mathrm{C}$ with a constant heating rate of $20{ }^{\circ} \mathrm{C} / \mathrm{min}$, directly followed by cooling to room temperature.

X-ray photoelectron spectroscopy (XPS) spectra were acquired using a Physical Systems Quantum 2000 spectrometer with monochromatic Al Ka radiation. Energy calibration was carried out on $\mathrm{Au}$ and $\mathrm{Ag}$ reference samples. Quantitative analyses were carried out using depth profiles of the coatings, acquired by $\mathrm{Ar}^{+}$-ion sputtering over an area of $1 \times 1$ $\mathrm{mm}^{2}$, with ions having energy of $1 \mathrm{keV}$ and sensitivity factors given by Physical Electronics Inc. software MultiPak V6.1A [10]. High resolution spectra were acquired after sputter etching of the sample surface for 15 min over an area of $1 \times 1 \mathrm{~mm}^{2}$ using 200 $\mathrm{eV} \mathrm{Ar}^{+}$ions. The XPS analysis area was set to a diameter of $200 \mu \mathrm{m}$ in all measurements.

Transmission electron microscopy (TEM), high-resolution TEM (HRTEM), and scanning TEM (STEM) images were obtained on a Tecnai $\mathrm{G}^{2} 20$ U-Twin $200 \mathrm{kV}$ FEGTEM. Analytical TEM was performed using energy-dispersive x-ray spectroscopy (EDX) in STEM mode. Focused ion beam (FIB) was used to prepare the cross-sectional sample. 
This TEM sample was prepared thicker than optimal for high-resolution imaging since the AgI decomposed in the near-surface sample region when imaged with a focused electron beam, as seen also in [11]. In an alternative sample preparation method, we prepared powder from the coatings by scratching with a scalpel. The powder was placed in an ultrasonic bath for $60 \mathrm{~s}$ for grain separation, before it was collected on a $\mathrm{Cu}$ grid. This resulted in areas in the sample that were electron-transparent.

Nanoindentation experiments were performed on an Umis 2000 instrument equipped with a Berkovich indenter. The hardness was calculated with the Oliver-Pharr method [12] as an average from 49 indents performed at loads of $0.5 \mathrm{mN}$.

A Tribometer from CSM instruments SA was used for pin-on-disc testing. In this setup, an Ag pin with a cylindrical surface, machined from one end of the pin and an applied load of $10 \mathrm{~N}$ was the static part, and the AgI plated sample is the moving part. One operation is performed when the pin is sliding back and forth on top of the sample creating a linear wear track (10 $\mathrm{mm}$ long and $2 \mathrm{~mm}$ wide), with a maximum speed of 8 $\mathrm{cm} / \mathrm{s}$, see Figure 1a. The sliding direction is perpendicular to the axis of the pin. The linear sliding approach was chosen since it mimics a real sliding electrical contact application. The friction coefficient was measured continuously during the wear testing, with an accuracy of $0.1 \%$. Tests were performed on 5 coupons with 5 pins with either 2500, 5000, 7500, and 10000 operations, and until the AgI coating was worn through (life-time testing). 


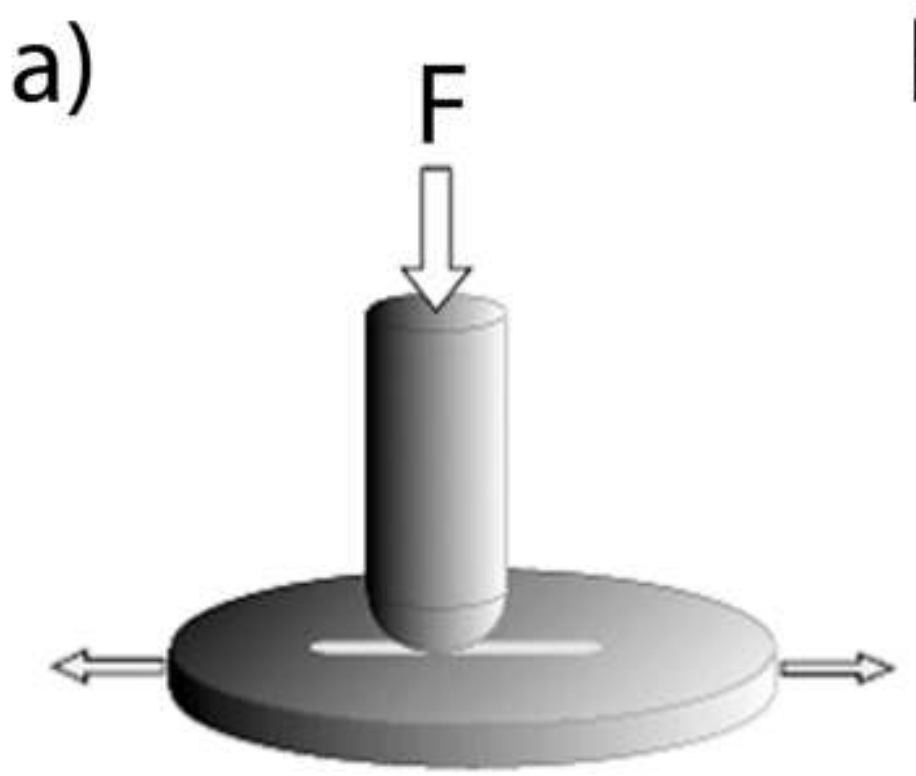

b)

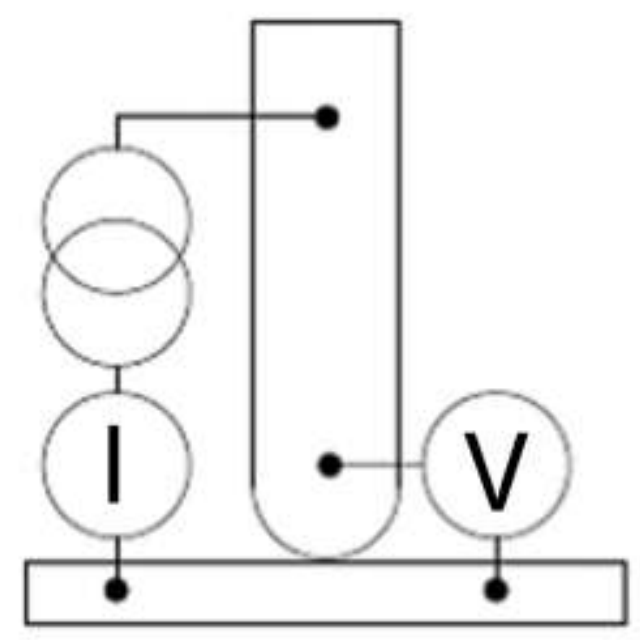

Figure 1. Schematic image over the tribometer a) the pin-on-disc setup, and b) the contact resistance setup. The friction coefficient and the contact resistance are measured simultaneously.

The contact resistance was measured simultaneously with the pin-on-disc-test by a fourterminal setup, see Figure 1b. A current of $10 \mathrm{~A}$ is applied and the voltage drop is measured, the contact resistance is measured with an accuracy of $0.03 \%$. In this setup, there are contributions from the resistance in the pin, and a leakage current. The contribution from the leakage current is negligibly small, and the resistance in the pin is constant and very low, so in principle the contact resistance is measured. The contact resistance for the Ag reference sample could not be made simultaneously with the tribology test since our tribology/electrical contact setup is constructed to stop at friction coefficient $>1$, and since the friction coefficient is 1.2 for $\mathrm{Ag}$ vs. $\mathrm{Ag}$ plated $\mathrm{Cu}$ the setup only worked for $\sim 10$ operations, which made it difficult to measure the Rc properly. However, in order to have reference values the contact resistance versus load was measured with the load of $10 \mathrm{~N}$. 


\section{Results}

Figure 2 shows $\mathrm{x}$-ray diffraction patterns of the AgI coating in as-deposited and annealed states. At room temperature, the $\mathrm{AgI}$ is in the hexagonal $(\beta-\mathrm{AgI})$ structure. The $\mathrm{Ag}$ peak observed in the patterns is from the substrate. When the sample is annealed to $140{ }^{\circ} \mathrm{C}$ (see Fig 1a), the $\beta$-AgI peak intensities decrease, and when the temperature is increased to $145^{\circ} \mathrm{C}$, only a faint $\beta$-AgI 110 peak remains. Instead, the cubic $\mathrm{AgI}(\alpha-\mathrm{AgI})$ forms. At $150{ }^{\circ} \mathrm{C}$, the hexagonal $\mathrm{AgI}$ is completely transformed to its cubic phase, in agreement with literature $[13,14]$. The phase transformation is observed to be reversible, since the $\mathrm{AgI}$ returns to its hexagonal phase when cooling back to room temperature. For annealing at higher temperatures (Figure 2b), the AgI coating decomposes at temperatures between 300 and $400{ }^{\circ} \mathrm{C}$ as judged by the formation of pure $\mathrm{Ag}$.

Figure 3 shows DSC, TG and MS measurements on AgI powder. In the DSC graph it is observed that the phase transformation from $\beta$-AgI to $\alpha-\mathrm{AgI}$ take place at $147{ }^{\circ} \mathrm{C}$, which is consistent with XRD and literature [13,14]. An exothermal reaction occurs from this phase transformation until AgI melts at $542{ }^{\circ} \mathrm{C}$. From the TG graph it is observed that the mass is constant up to $\sim 147{ }^{\circ} \mathrm{C}$, above which a loss of mass occurs continuously to $\sim 542{ }^{\circ} \mathrm{C}$, where the mass loss accelerates. From the MS graph it is observed that $\mathrm{I}_{2}$ and $\mathrm{H}_{2} \mathrm{O}$ evaporate. The $\mathrm{H}_{2} \mathrm{O}$ signal is $\sim 375$ times lower than the $\mathrm{I}_{2}$ signal. Both signals have a peak at $\sim 415{ }^{\circ} \mathrm{C}$, and the $\mathrm{I}_{2}$ signal remains at $600{ }^{\circ} \mathrm{C}$ in contrary to the $\mathrm{H}_{2} \mathrm{O}$ signal. 
a)

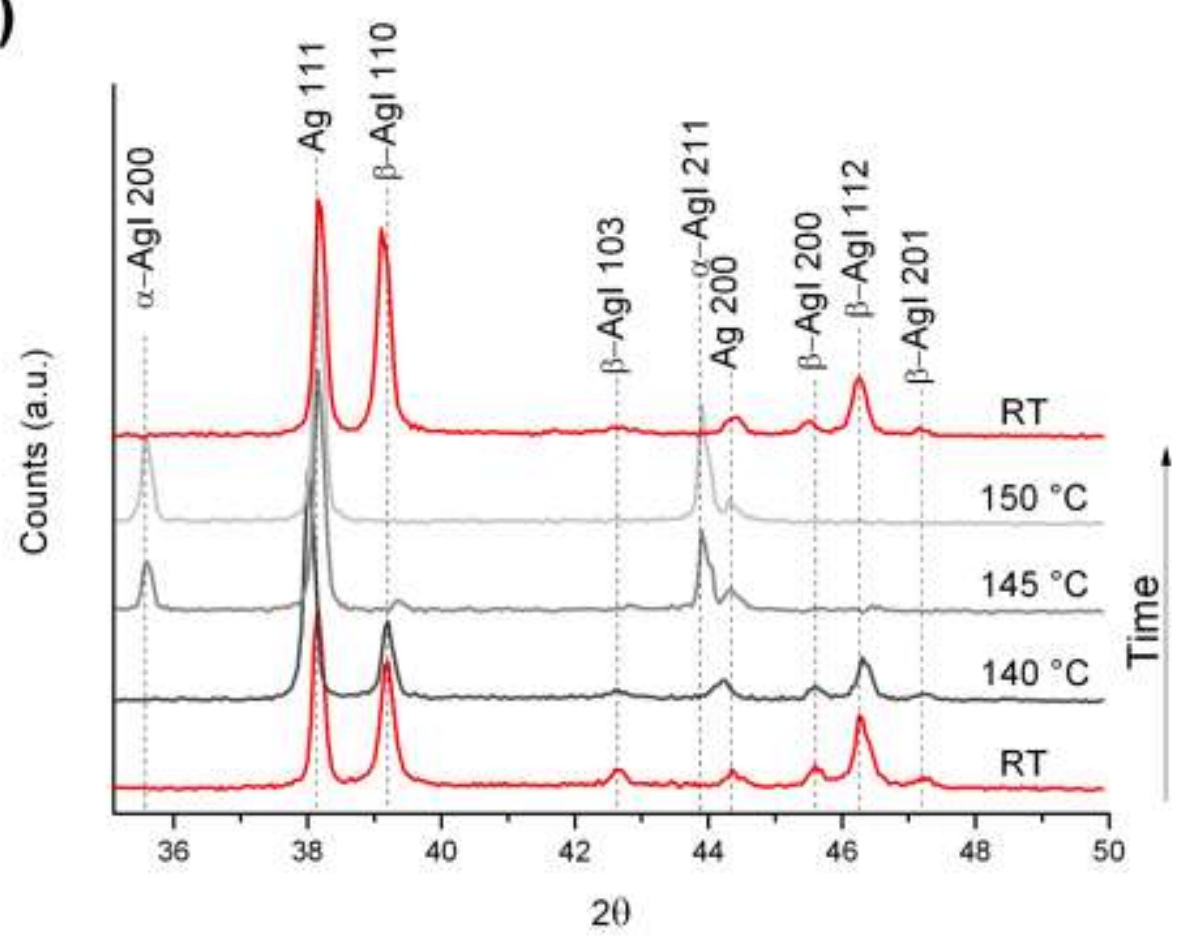

b)

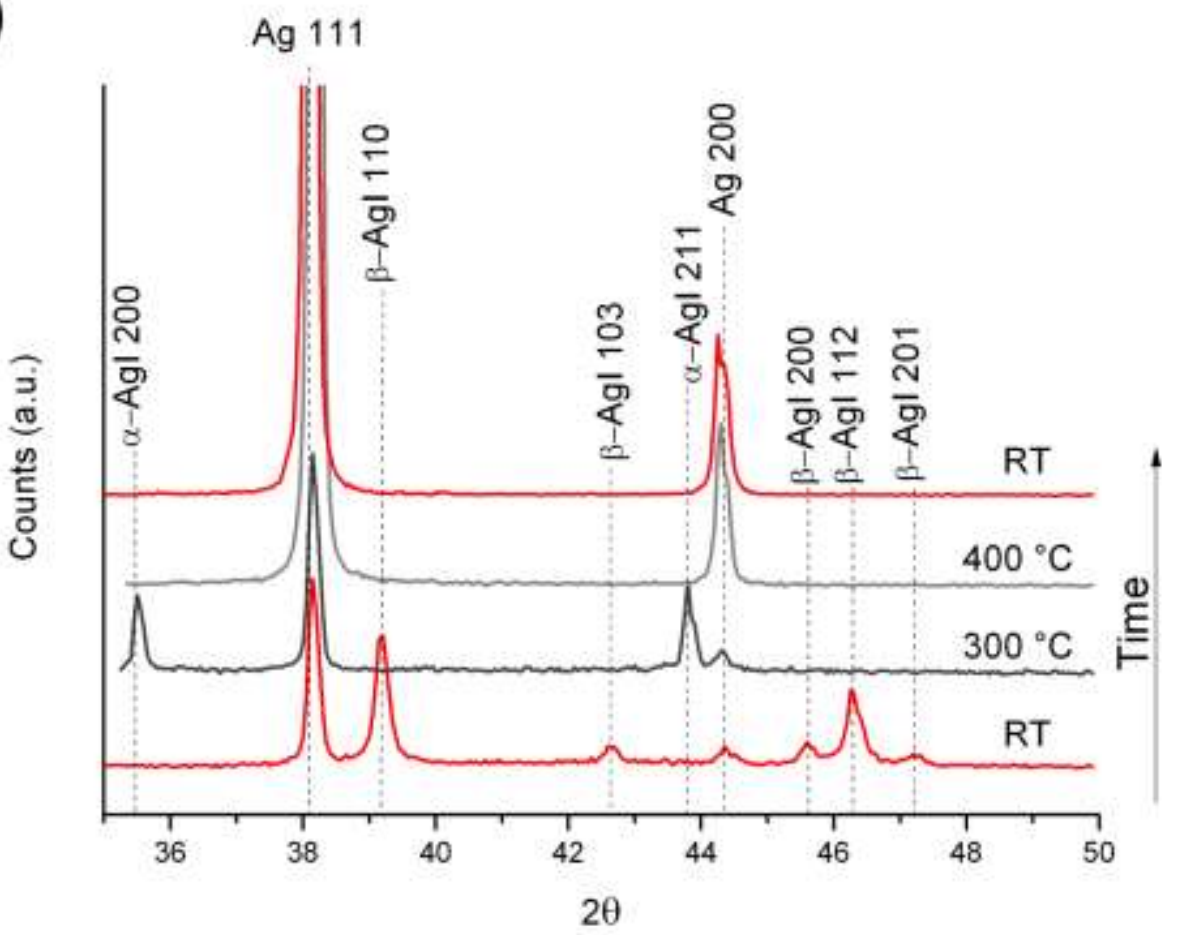

Figure 2. XRD diffraction pattern from an AgI coating annealed at different temperatures. 


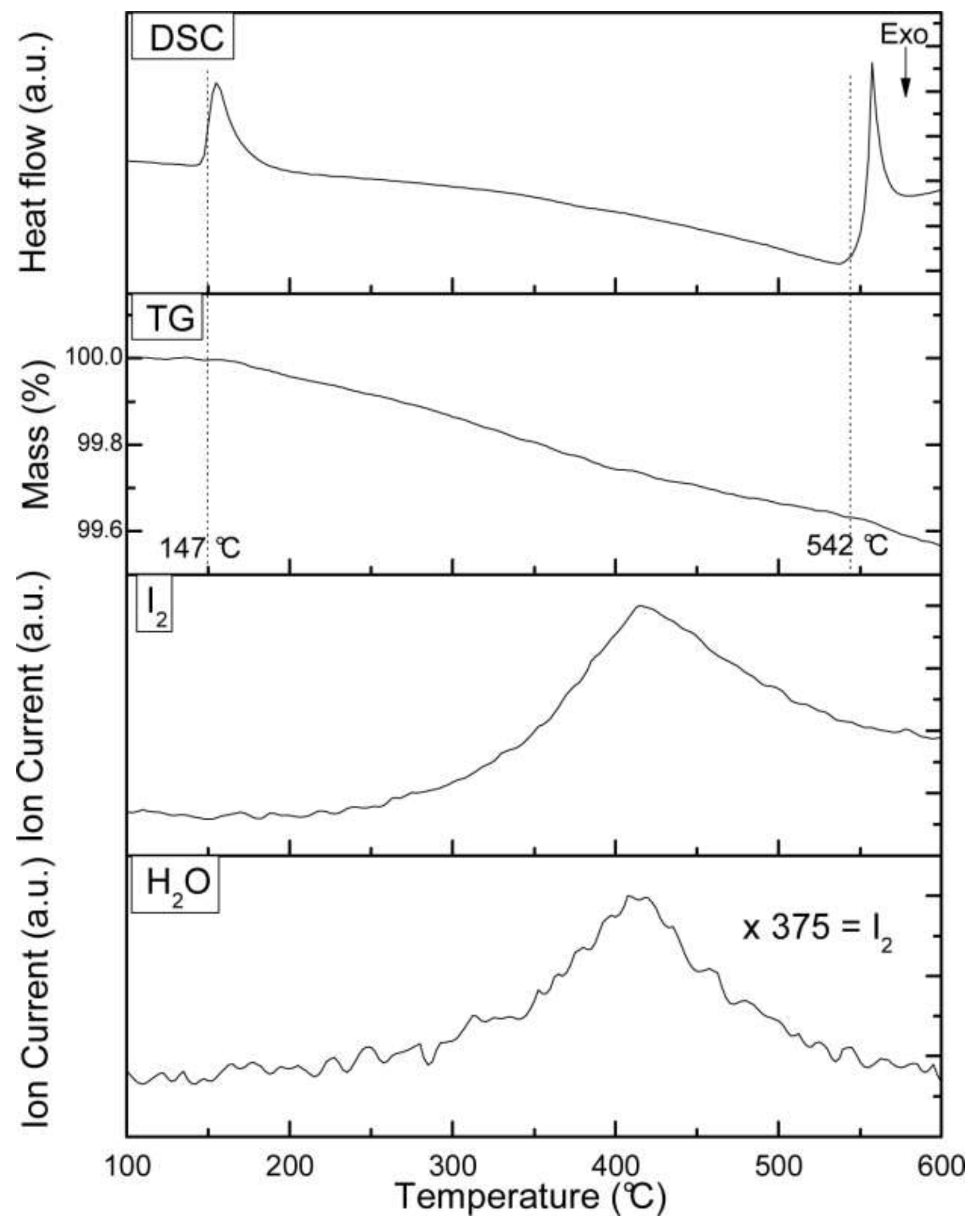

Figure 3. Differential scanning calorimetry, thermogravimetry, and mass spectrometry measurements of the AgI coating. 
Figure 4 shows a STEM image with an EDX elemental map of a typical AgI coating on an electroplated Ag layer. The elemental map shows that Ag and I are homogenously distributed, as expected for the AgI compound, and that there are pores as represented by the darker patches. The AgI coating is $\sim 2 \mu \mathrm{m}$ thick.

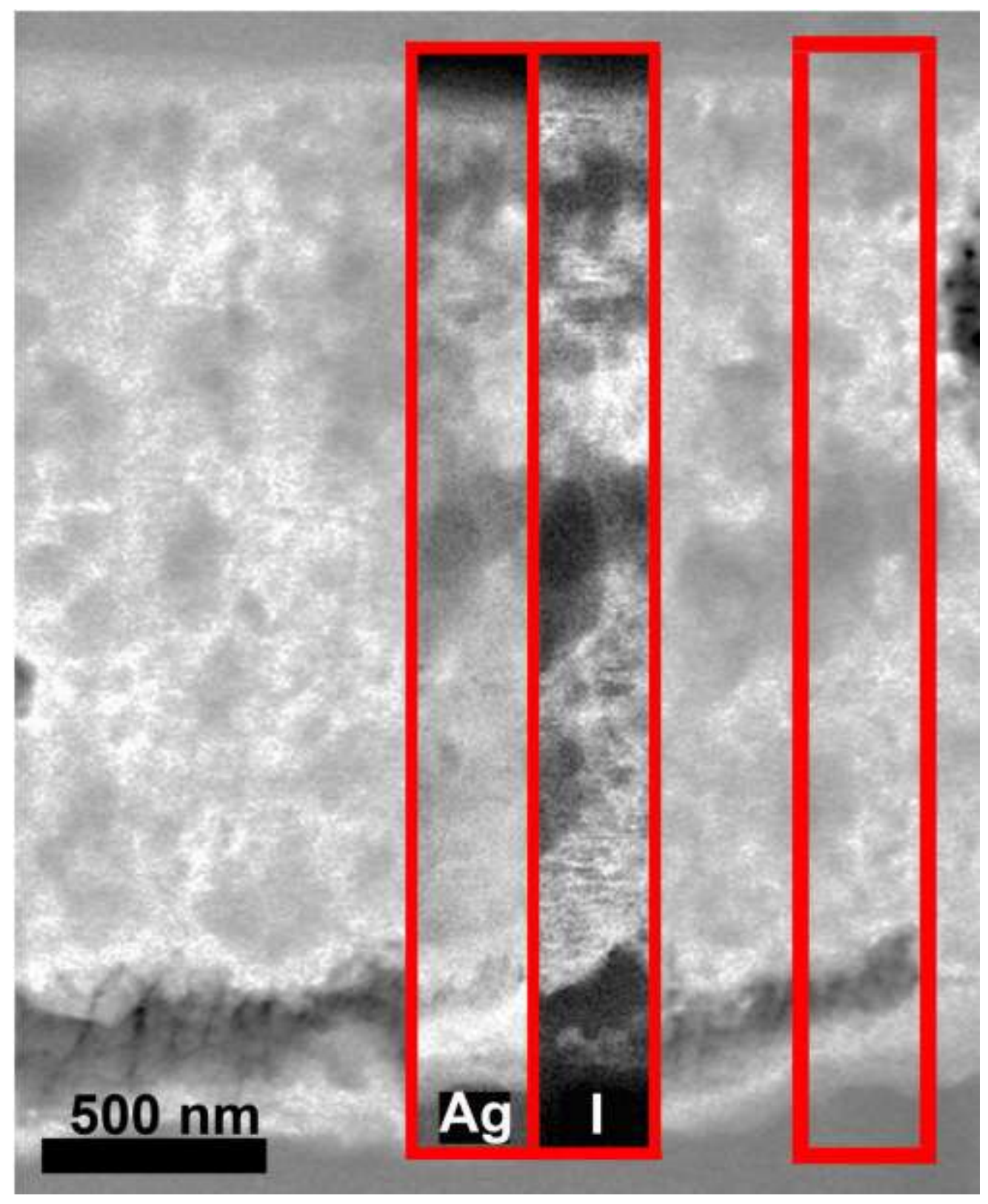

Figure 4. STEM image with an EDX elemental map of the AgI coating. 
Fel! Hittar inte referenskälla.a shows an overview TEM micrograph with corresponding selected area electron diffraction (SAED) pattern of the AgI powder sample. The coating is composed of spherical particles and is porous, consistent with Figure 4. SAED shows that the particles consist of crystalline $\beta$-AgI grains. Fel! Hittar inte referenskälla.b shows separate $\beta$-AgI grains with sizes between $5 \mathrm{~nm}$ and $50 \mathrm{~nm}$. Small particles can be seen decorating the $\beta$-AgI grains. Fel! Hittar inte referenskälla.c shows a low-electron dose fast fourier transform filtered HRTEM image with corresponding SAED pattern in the [0001] projection of an isolated AgI grain. These results prove that the $\mathrm{AgI}$ is in the hexagonal structure, and thus predominantly unaffected by the electron exposure.

Figure 6 shows the measured contact resistance of an AgI coating during 10000 operations in the pin-on-disc test. The contact resistance is initially high, but after $\sim 300$ operations it drops under $100 \mu \Omega$, and stays rather constant for 10000 operations. The contact resistance curves differ slightly for the tests on four similar samples (not shown), so to be sure that the contact resistance has dropped, 500 operations are necessary. The contact resistance for $\mathrm{Ag}$ against $\mathrm{Ag}$ plated $\mathrm{Cu}$ at $10 \mathrm{~N}$ is $\sim 85 \mu \Omega$.

$\mathrm{Ag}$ has a friction coefficient of $\sim 1.2$ against the $\mathrm{Ag}$ pin (not shown). Figure 7 shows that the friction coefficient for the AgI coating decreases to $~ 0.4$. The results from four AgI coatings deposited on similar $\mathrm{Ag}$ coated $\mathrm{Cu}$ coupons were the same (not shown), 
confirming the reproducibility of this result. The friction coefficient was stable at 0.4 under 1.900.000 operations until it drastically increased over 1 (not shown). 


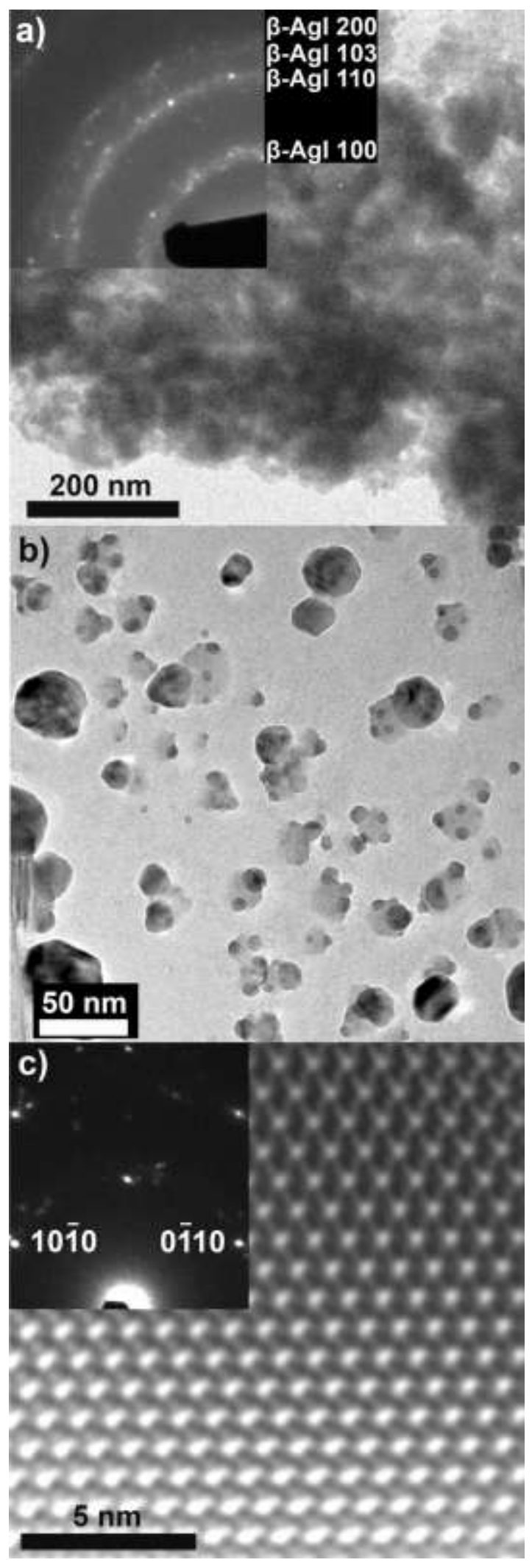

Figure 5. TEM images with corresponding SAED pattern and HRTEM image of the AgI coating. 


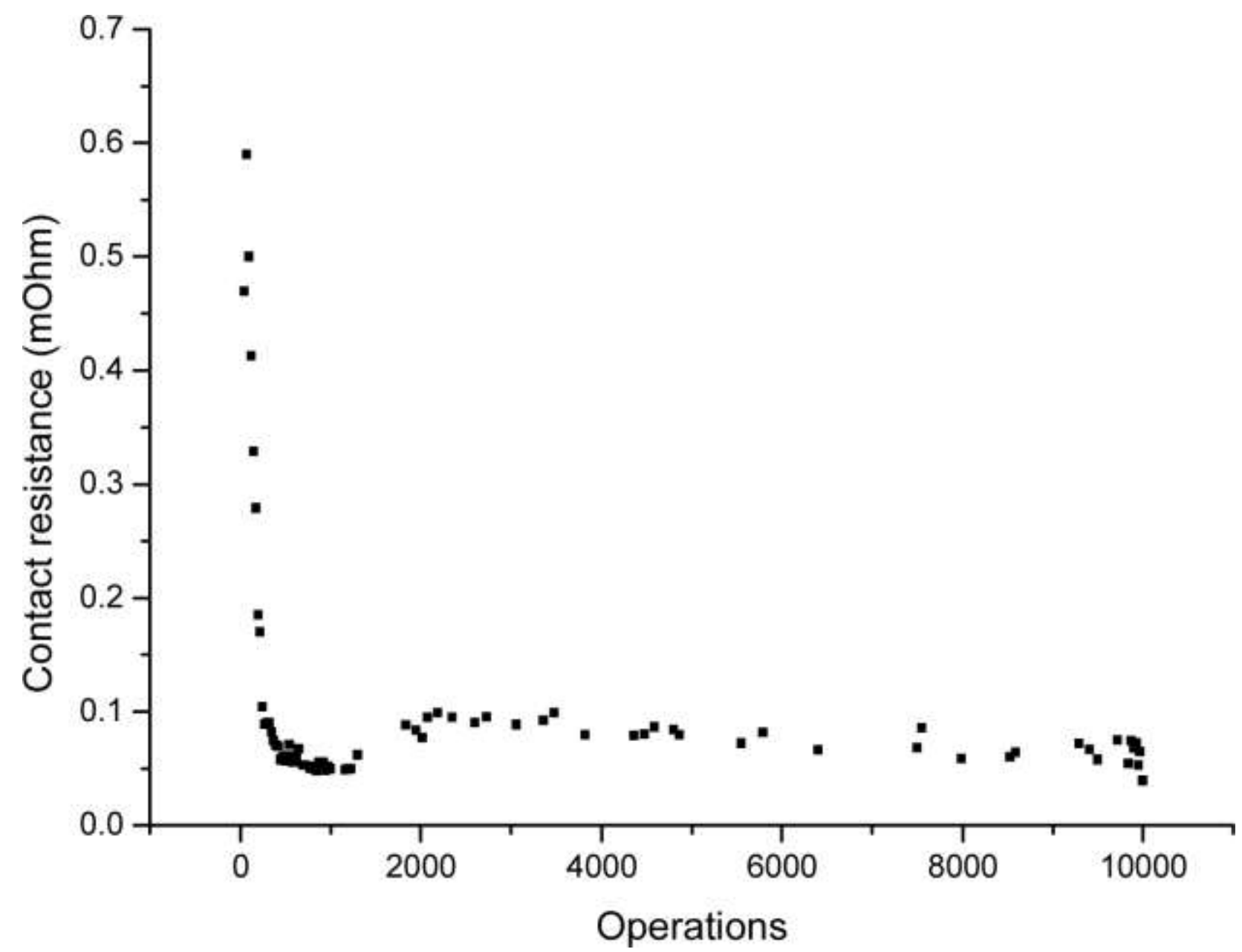

Figure 6. Contact resistance of the AgI coating deposited on an Ag coated Cu coupon, during the tribological test.

Table 1 shows the composition of the coating and the wear track after 10000 operations. The coating is stoichiometric and there is still some iodine left in the wear track. However, the $\mathrm{Ag} / \mathrm{I}$ ratio is $\sim 3$ in the wear track, rather than the 1:1 of the AgI compound.

Figure 8 shows light optical images in different magnifications. It can be seen that after 5000 operations the wear track in the AgI coating is $10 \mathrm{~mm}$ long and $2 \mathrm{~mm}$ wide. In higher magnification it is observed that the wear track consists of bright and dark lines. 


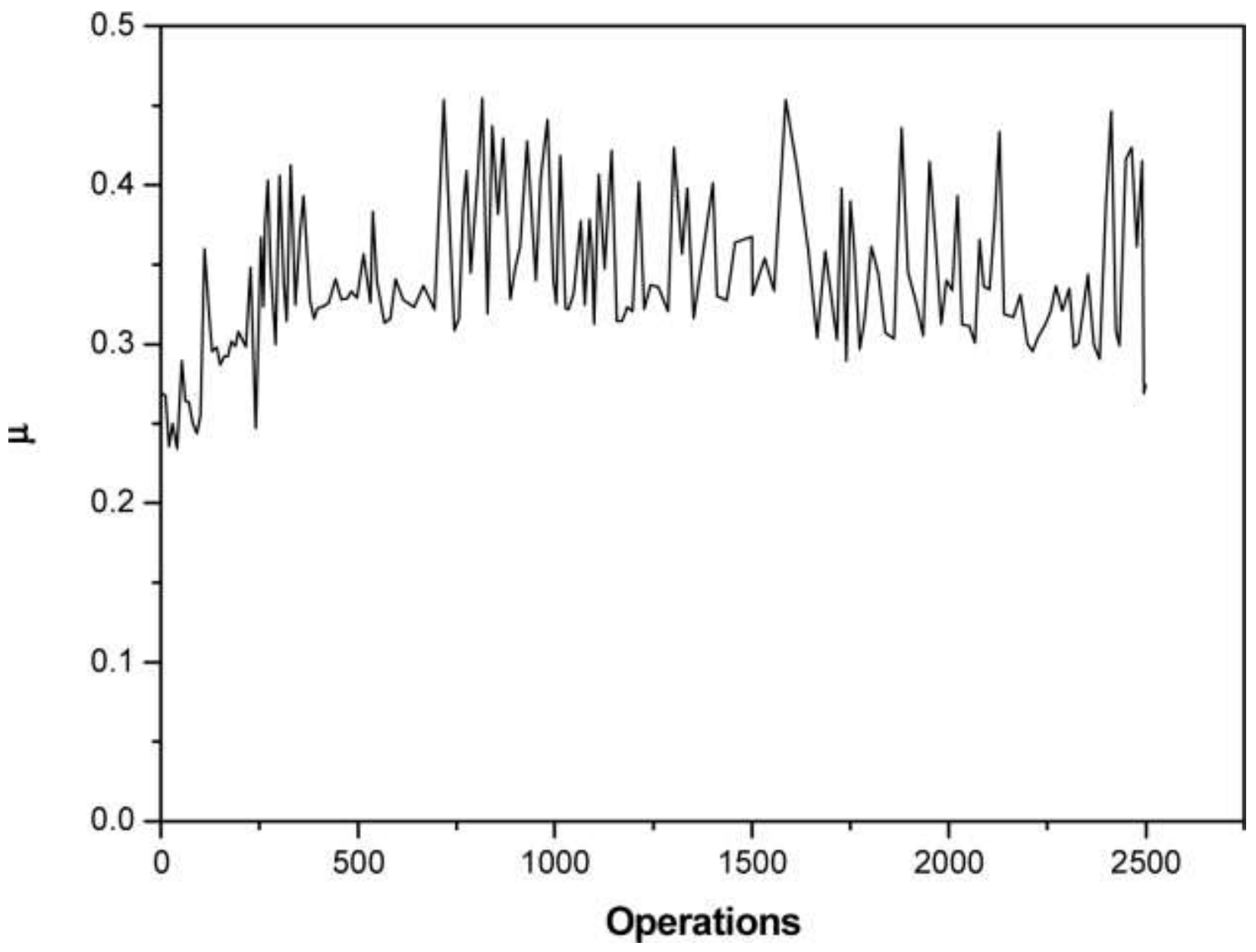

Figure 7. Friction coefficient from the center in the wear track, measured during 2500 operations.

Figure 9 shows the Ag3d and the I3d regions of the XPS spectra from the as-deposited coating and the 10000 operation wear track on the same sample. From the Ag3d region it is difficult to distinguish between the Ag-Ag and Ag-I bonds. However, it is observed that the coating has less Ag and AgI signature than the wear track. The I3d region shows that the concentration of I-Ag bonds in the wear track is decreased. 


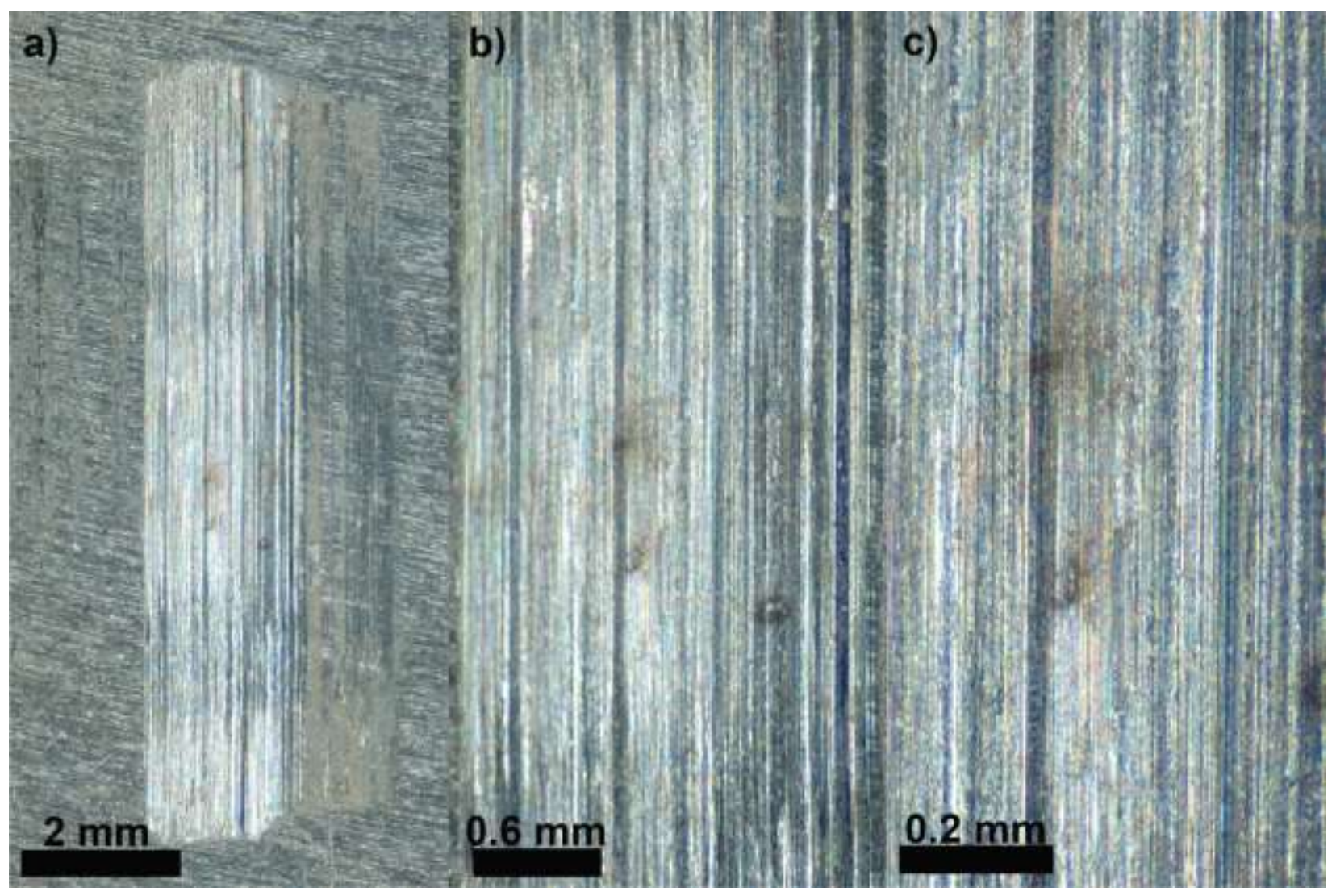

Figure 8. Light optical images of the wear track taken after 10.000 operations at different magnifications.

The hardness of these AgI coatings was $630 \mathrm{MPa}$, which is harder than pure bulk $\mathrm{Ag}$ ( 320 MPa) [15], but softer than bulk AgI ( 1 GPa) [16]. 

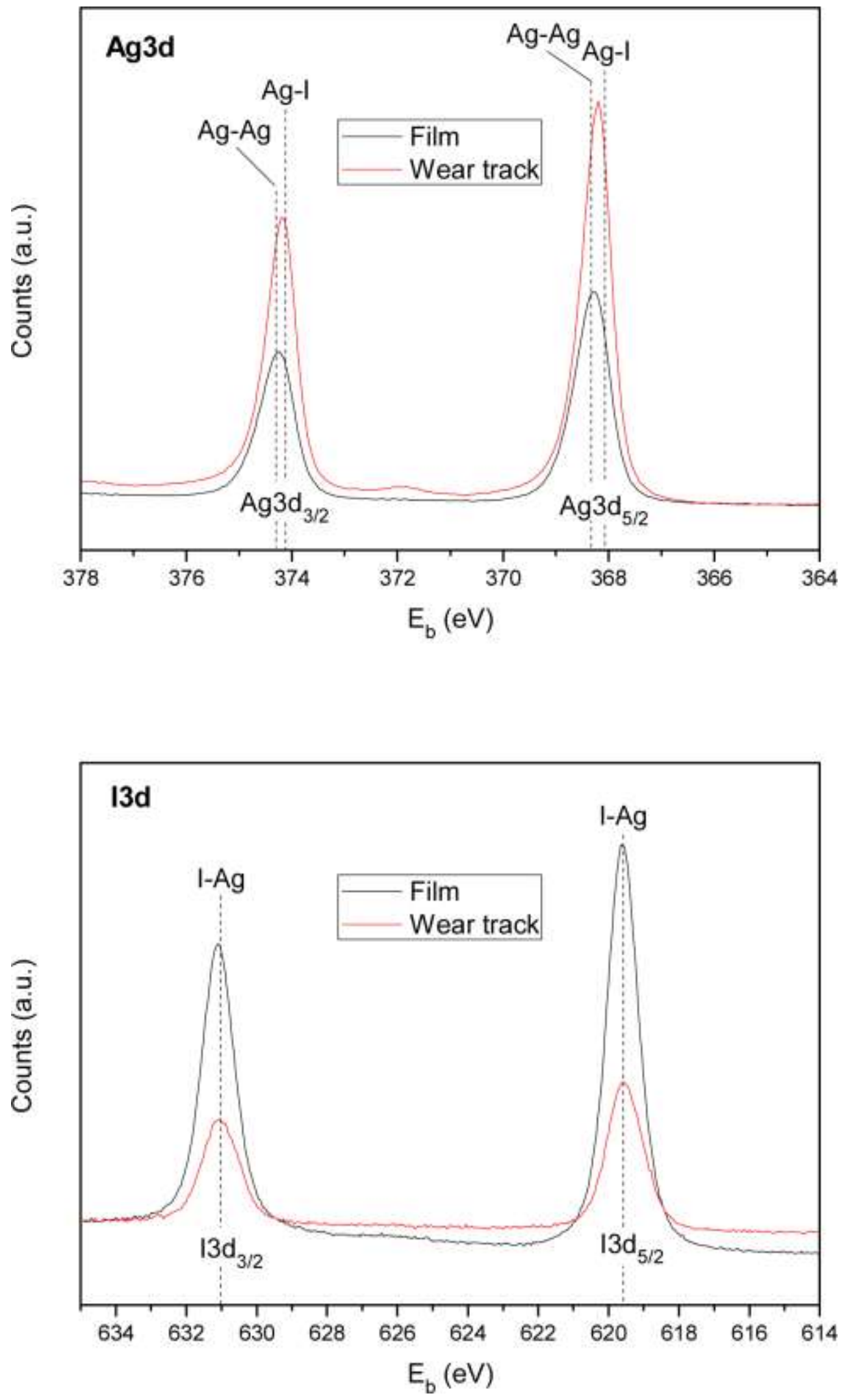

Figure 9. XPS spectra from a) the Ag3d region, and b) the I3d region. 


\section{Discussion}

It has been reported that $\alpha-\mathrm{AgI}$ is thermally stable in the bulk up to $555^{\circ} \mathrm{C}$ [13]. In the present paper, however, the $\alpha$-AgI phase that forms in the coatings annealed to above $\sim 150{ }^{\circ} \mathrm{C}$ decomposes between $300-400{ }^{\circ} \mathrm{C}$ in vacuum at the base pressure of $10^{-3} \mathrm{~Pa}$, when annealed for $\sim 3.75 \mathrm{~h}\left(75 \mathrm{~min}\right.$ at $200{ }^{\circ} \mathrm{C}, 75 \mathrm{~min}$ at $300{ }^{\circ} \mathrm{C}$, and $75 \mathrm{~min}$ at $\left.400{ }^{\circ} \mathrm{C}\right)$. In the DSC measurements a mass loss is initially detected at $\sim 150{ }^{\circ} \mathrm{C}$ on a small scale. The mass loss in Figure 3 is just an indication because of the measured sample contains a lot of Ag powder since the sample is scratched from the surface, which reduces the actual percentage mass loss. AgI starts to decompose already at $\sim 150{ }^{\circ} \mathrm{C}$, and the decomposition rate is increased in the liquid state. When the phase transformation occurs, AgI decomposes slowly, and both $\mathrm{H}_{2} \mathrm{O}$ and $\mathrm{I}_{2}$ begin to evaporate, $\mathrm{I}_{2}$ probably at its boiling point $\left(184{ }^{\circ} \mathrm{C}\right)$. While the $\mathrm{I}_{2}$ and $\mathrm{H}_{2} \mathrm{O}$ evaporation continue up in temperature and peak at $400{ }^{\circ} \mathrm{C}$, there is likely a complex-bonded hydroxide in the samples. In the DSC measurement where the temperature is increased with $20{ }^{\circ} \mathrm{C} / \mathrm{min}$ up to $600{ }^{\circ} \mathrm{C}$ in an $\mathrm{Ar}$ atmosphere, the effective time at temperatures above $150{ }^{\circ} \mathrm{C}$ is shorter compared with XRD. The slower decomposition rate in DSC compared to XRD may also depend on the difference in base pressure since it is known that lower pressure in the XRD measurements decreases the boiling point and thus increases the evaporation rate.

AgI also decomposes when it is exposed to the electron beam in the TEM, because the electron beam heats the coating locally. The small particles decorating the $\beta$-AgI grains (Fel! Hittar inte referenskälla.b) are the effect of AgI decomposition when the sample is exposed to the electron beam. Although the low-electron dose technique is used, these 
particles grow on each grain, before the grain decomposes, and in some cases evaporates. This effect is only observed on the small and thin $\beta$-AgI grains in Fel! Hittar inte referenskälla.b, probably because of their relatively large surface-to-volume ratio. In fact, we could follow the decomposition of isolated AgI grains over time of minutes in the microscope.

Considering the temperature-sensitivity of AgI coatings, the formation of so called "hotspots" between the contact members should be considered when current is transported through the contact. The temperature in the contact spots (known as a-spots) can be estimated by:

$$
T_{\max }^{2}=T_{0}^{2}+V^{2} / 4 L
$$

where $T_{\max }$ is the maximum temperature in the contact spot, $T_{0}$ is the conductor ambient temperature, $V$ is the voltage drop, and $L$ is the Lorenz constant $[1,17]$. However, if the $T_{\max }$ is estimated in the AgI coating, at ambient temperature, and at voltage drops from the contact resistance results below $(0.001 \mathrm{~V})$, the temperature will not increase by more than $1{ }^{\circ} \mathrm{C}$, and no phase transformation occurs. However, when a current is applied, the local temperature can easily exceed $150{ }^{\circ} \mathrm{C}$ in very many contact situations. Ag-Ag e.g., often suffers from local melting/welding. In fact, this small temperature increase is remarkable since it is expected to be heated to temperatures $>147{ }^{\circ} \mathrm{C}$ locally when a current is applied on the contact. However, if the current is increased from $10 \mathrm{~A}$ to $100 \mathrm{~A}$, the temperature will be increased significantly. So, it depends on the application, which makes this phenomenon important to consider when $\mathrm{AgI}$ is used as a solid lubricant. 
The decreased friction coefficient of the AgI coating compared with Ag, is probably because the $\mathrm{AgI}$ is more resistant to welding than $\mathrm{Ag}$ towards an $\mathrm{Ag}$ counterpart. The contact resistance for $\mathrm{AgI}$ is initially high. However, when these contacts are operated for $\sim 500$ operations, the contact resistance drops to below $100 \mu \Omega$, similar as Ag against Ag. In Figure 8, light optical images show that the surfaces develop areas with two clearly separated compositions after wear, where bright areas probably correspond to wornthrough areas, and thus Ag, and the darker areas are probably AgI. From the TEM images it seems that the AgI coating consist of agglomerated AgI grains (Fel! Hittar inte referenskälla.a). When the AgI powder was put in an ultrasonic bath, the AgI grains are all separated (Fel! Hittar inte referenskälla.b). Therefore, we infer that the as-deposited coatings consist of relatively weakly agglomerated $\beta$-AgI grains. In the wear test, the AgI coating separates and gather in some areas, at the same time as Ag from the under lying layer is exposed on the surface, which would explain the simultaneously low contact resistance and low friction. The condition that $\mathrm{Ag}$ is exposed in the wear track with residual AgI after 10000 operations, can explain the persistently low coefficient of friction (0.4) and low contact resistance $(<100 \mu \Omega)$.

The life time test on a typical sample showed that the friction coefficient was well below 1.2, as long as AgI remained on the surface. In fact, the coatings lasted up to 1.900 .000 operations with the friction coefficient stable at $\sim 0.4$, before it rapidly increased to $>1$. Correspondingly, the AgI coating was worn through. We infer that the useful properties of $\mathrm{AgI}$ in the coatings are that it both decreases the friction coefficient and improves the wear resistance of $\mathrm{Ag}$, which leads to an increased life time of the contact. 


\section{Conclusions}

AgI coatings in the hexagonal $\beta$-phase can be deposited on an $\mathrm{Ag}$ plated $\mathrm{Cu}$ coupon by electroplating. The coating transforms to the cubic $\alpha$-phase at $\sim 150{ }^{\circ} \mathrm{C}$ and decomposes into $\mathrm{Ag}$ and iodine at an accelerating rate up to the $\mathrm{AgI}$ melting temperature. The $\mathrm{AgI}$ coating works as a solid lubricant by reducing the friction coefficient of Ag from $\sim 1.2$ to $\sim 0.4$, and at the same time has a contact resistance lower than $100 \mu \Omega$ after $\sim 500$ operations. This is explained by the microstructure of the coatings with relatively weakly agglomerated AgI grains. The contact resistance for $\mathrm{AgI}$ is much higher than for $\mathrm{Ag}$, however, after $\sim 500$ operations enough AgI grains has been deagglomerated that Ag from the underlying deposit is exposed on the contact surface. The presence of Ag decreases the contact resistance dramatically, and the remaining AgI keeps the friction coefficient at the lower level until it is completely worn off after 1.900 .000 operations. If AgI coatings should be used as solid lubricants, it is important to calculate the temperature in the contact spots for the applications conditions since AgI coatings starts to decompose at $\sim 150{ }^{\circ} \mathrm{C}$ into $\mathrm{Ag}$ and iodine at an accelerating rate up to the $\mathrm{AgI}$ melting temperature.

\section{Acknowledgments}

We acknowledge Nils Nedfors and Ulf Jansson at Uppsala University for discussions and technical assistance concerning the XPS measurements. The work was financially 
supported by the VINNOVA VINN Excellence Centre in Research and Innovation on Functional Nanoscale Materials, FunMat.

Table 1. Composition of the AgI coating and the wear track after 10000 operations (units is at.\%) measured with XPS. The contamination is mainly $\mathrm{C}$ and $\mathrm{O}$.

$\begin{array}{lccc} & \mathrm{Ag} & \mathrm{I} & \text { Contamination } \\ \text { Coating } & 45.1 & 45.5 & 9.4 \\ \text { Wear track } & 66 & 24.2 & 9.8\end{array}$

[1] Slade, P. G., ed., Electrical Contacts - Principles and Applications, CRC Press, Taylor \& Francis Group, New York (1999).

[2] Kassman Rudolphi, Å., Jacobson, S. : Gross plastic fretting mechanical deterioration of silver coated electrical contacts. Wear 201, 244-254 (1996).

[3] Lauridsen, J., Eklund, P., Joelsson, T., Ljungcrantz, H., Öberg, Å., Lewin, E., Jansson, U., Beckers, M., Högberg, H., Hultman, L. : High-rate deposition of amorphous and nanocomposite $\mathrm{Ti}-\mathrm{Si}-\mathrm{C}$ multifunctional coatings. Surf. Coat. Technol. 205, 299-305 (2010).

[4] Lauridsen, J., Eklund, P., Jensen, J., Ljungcrantz, H., Öberg, Å., Lewin, E., Jansson, U., Flink, A., Högberg, H., Hultman, L. : Microstructure evolution of Ti$\mathrm{Si}-\mathrm{C}-\mathrm{Ag}$ nanocomposite coatings deposited by DC magnetron sputtering. Acta Materialia 58, 6592-6599 (2010).

[5] Eklund, P., Emmerlich, J., Högberg, H., Wilhelmsson, O., Isberg, P., Birch, J., Persson, P. O. Å., Jansson, U., Hultman, L. : Structural, electrical, and mechanical 
properties of nc-TiC a-SiC nanocomposite thin films. J. Vac. Sci. Technol. B 23, 2486-2495 (2005).

[6] Lewin, E., Olsson, E., André, B., Joelsson, T., Öberg, Å., Wiklund, U., Ljungcrantz, H., Jansson, U. : Industrialisation Study of Nanocomposite ncTiC/a-C Coatings for Electrical Contact Applications. Plasma Processes and Polymers 6, S928-S934 (2009).

[7] Štěpina, V., Veselý, V., Tribology series, 23, Lubricants and special fluids, Elsevier, Amsterdam (1992).

[8] Gupta, S., Filimonov, D., Palanisamy, T., El-Raghy, T., Barsoum, M. W. : $\mathrm{Ta}_{2} \mathrm{AlC}$ and $\mathrm{Cr}_{2} \mathrm{AlC}$ Ag-based composites- New solid lubricant materials for use over a wide temperature range against Ni-based superalloys and alumina. Wear 262, 1479-1489 (2007).

[9] Arnell, S., Andersson, G., : Silver Iodide as a Solid Lubricant for Power Contacts. Proc. 47th IEEE Holm Conference on Electrical Contacts, Montreal, p. 239-244 (2001).

[10] Operator's Multipak Software Manual, Physical Electronics Inc., 2000.

[11] Sáfrán, G., Geszti, O., Radnóczi, G., Barna, P. B., Tóth, K. : TEM study of the structure and morphology of AgI crystals formed on $\mathrm{Ag}$ (001), (011) and (111) thin films. Thin Solid Films 259, 96-104 (1995).

[12] Oliver, W. C., Pharr, G. M. : An improved technique for determining hardness and elastic modulus using load and displacement sensing indentation experiments. J. Mater. Res. 7, 1564-1583 (1992). 
[13] Schneer, C. J., Whiting, R. W. : Phase transformation and thermal hysteresis in the system AgI. The American Mineralogist 48, 737-758 (1963).

[14] Yoshiasa, A., Inaba, A., Ishii, T., Koto, K. : A phase transition of AgI at $150 \mathrm{~K}$. Solid State Ionics 79, 67-70 (1995).

[15] Yoo, J., Chung, H., Ko, J., Kim, H. : Effect of Au and Mg addition to Ag sheath on microstructure and superconducting properties of BSCCO-2223 tapes. Physica C 269, 109-114 (1996).

[16] Chowdari, B. V. R., Gopalakrishnan, R. : Investigations of $\mathrm{AgX:} \mathrm{Ag}_{2} \mathrm{O}$ : $\mathrm{MoO}_{3}: \mathrm{P}_{2} \mathrm{O}_{5}$ glassy system $(\mathrm{X}=\mathrm{I}, \mathrm{Br}, \mathrm{Cl})$. J. Non-Crys. Solids 105, 269-274 (1988).

[17] Holm, R., Electric contacts - Theory and applications, Reprint of the fourth completely rewritten edition, $1967,3^{\text {rd }}$ printing, Springer, Berlin (2000). 